DOI: https://doi.org/10.15688/jvolsu4.2017.1.3

UDC 94(420)“1457/1485”

Submitted: 23.09 .2016

LBC 63.3(0)4

Accepted: 14.12 .2016

\title{
THE SOCIAL STRUCTURE OF PARTICIPANTS OF THE BATTLE OF BLORE HEATH (SEPTEMBER 23, 1459)
}

\author{
Andrey G. Prazdnikov \\ Vyatka State Agrarian Academy, Kirov, Russian Federation
}

\begin{abstract}
The battle of Blore Heath which took place on September 23, 1459, marked the new stage of the Wars of Roses, which led to the change of dynasties at the English throne in less than two years. As it was not the clash of the main forces of House of Lancaster and House of York, the sources contain poor information about the battle's participants. However, the analysis different sources let identify the names of 22 participants. Prosopographic study of this group contributes to the study of social behavior models, the degree of influence of the Wars of Roses on English society, the activity of representatives of different social strata. The social structure of the group, most of which are the representatives of the English gentry, is the object of the article. There is information in the sources about the origin of the knights. The House of York under the command of Earl of Salisbury were mostly from Northern and North-Western counties (Yorkshire, Westmorland), whereas House of Lancaster formed their troops in Cheshire, Staffordshire and Lancashire. As a rule, officers in the army of the Earl of Salisbury, were in close personal or family ties with him. The study of further lives of the participants of the battle and biographies of their children showed that the adherence of the chosen dynasty was preserved by generations and change of the parties was rather a deviation from the norm. English nobility of the second half of the 15th century had a high opinion of the value of loyalty and honor.

Key words: Wars of Roses, battle of Blore Heath, House of Lancaster and House of York, social structure of participants.
\end{abstract}

УДК 94(420)“1457/1485”

Дата поступления статьи: 23.09.2016

ББК $63.3(0) 4$

Дата принятия статьи: 14.12.2016

\section{СОЦИАЛЬНЫЙ СОСТАВ УЧАСТНИКОВ СРАЖЕНИЯ ПРИ БЛОР ХИТ 23 СЕНТЯБРЯ 1459 ГОДА}

\author{
Андрей Геннадьевич Праздников \\ Вятская государственная сельскохозяйственная академия, г. Киров, Российская Федерация
}

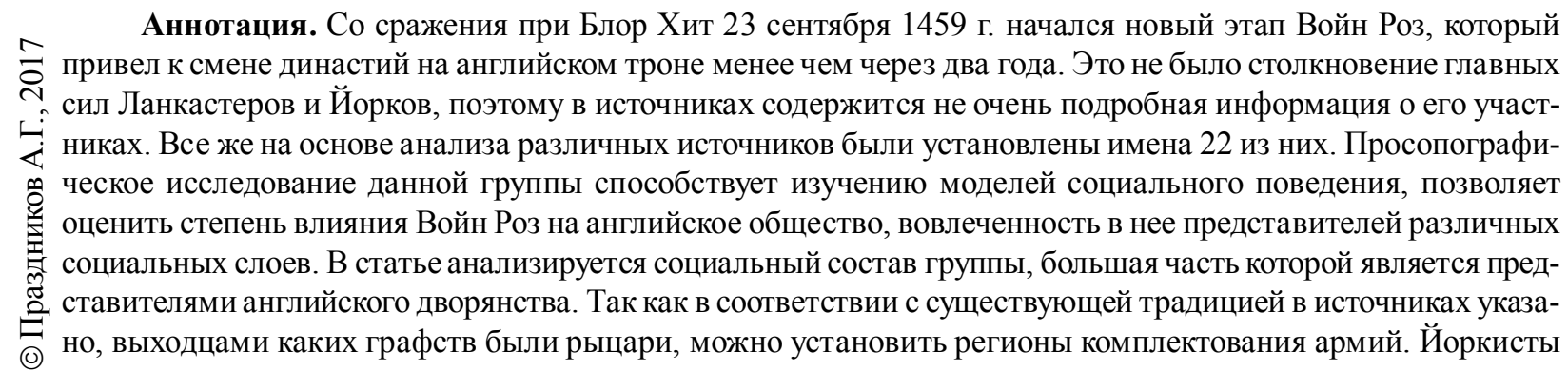


под командованием Ричарда Невилля, графа Солсбери, в основном были из северных и северо-западных графств (Йоркшир, Уэсморленд), тогда как ланкастерцы формировали свои отряды в Чешире, Стаффордшире и Ланкашире. Офицеры в армии графа Солсбери, как правило, состояли с ним в тесных личных или родственных связях. Изучение дальнейших судеб участников сражения и биографий их детей показало, что приверженность выбранной династии сохранялась из поколения в поколение, а смена стороны конфликта скорее была отклонением от нормы. Английские дворяне второй половины XV столетия высоко ставили ценности верности и чести.

Ключевые слова: Войны Роз, сражение при Блор Хит, Ланкастеры, Йорки, социальный состав участников.

Социально-политический конфликт в Англии второй половины XV в., известный как Войны Роз, не представлял собой непрерывную цепь военных действий. Если первая битва произошла в 1455 г. при Сент Олбансе, то следующее сражение - лишь в 1459 году. Однако именно с него начался новый этап противостояния, который в конечном итоге привел к смене династии на троне менее чем через два года. Речь идет о сражении при Блор Хит 23 сентября 1459 года.

В историографии Войн Роз давно ведется дискуссия о характере этого явления. Даются различные оценки: от династического конфликта и кровавой файды до гражданской войны. Для того чтобы оценить степень влияния рассматриваемых событий на общество и вовлеченность в них представителей различных социальных групп, необходимо располагать информацией персонального характера, увидеть конкретных людей с их мотивами. В большинстве случаев эта информация скрыта для исследователя, однако не абсолютно. Иногда прямо или косвенно она может быть обнаружена в свидетельствах современников или их ближайших потомков.

Сражение при Блор Хит не относится к числу крупнейших битв периода Войн Роз. Первое посвященное ему исследование появилось еще в 1912 году [18]. В новейших работах по английской истории второй половины $\mathrm{XV}$ в. оно, как правило, упоминается лишь в качестве краткого эпизода в конфликте Йорков и Ланкастеров $[8$, с. $57 ; 10$, с. 35$]$. Тем не менее изучение состава участников этого столкновения будет способствовать изучению социальных практик того времени.

Источники по сражению при Блор Хит по характеру могут быть разделены на несколько типов. Прежде всего это официальный документ - «Парламентские свитки», которые составлялись секретарями парламентов и со- держат описание их работы и принятых решений. В Англии XV в. существовала традиция объявления государственными изменниками и лишения личных и имущественных прав тех лиц, которые были признаны в совершении преступлений против короны, что должно было закрепляться парламентским актом. С 20 ноября по 20 декабря в Ковентри проходил так называемый «Парламент дьяволов», в котором объявление государственными изменниками было впервые применено с начала Войн Роз. Под эту санкцию попали 27 человек, еще 5 человек были помилованы, из них 8 человек были обвинены за участие в сражении при Блор Хит [16, с. 349].

Отдельные имена участников сражения могут содержаться в различных документах. Так, сообщение о гибели в бою рыцаря Уильяма Троутбека удалось обнаружить в ответе на жалобу, поданную на имя короля его вдовой Маргарет, сетующей на недостаток средств к существованию [5, с. 582].

Наиболее многочисленными источниками являются хроники, и события в них описаны неодинаково. Самое подробное описание находим в «Хронике Грегори» [6, с. 204]. До 1452 г. она написана лондонским мэром Уильямом Грегори, по имени которого и получила свое название, затем анонимный автор, но тоже столичный житель, продолжил ее и довел до 1469 года. В хронике названы имена 10 участников.

Описание сражения также есть в «Собрании хроник и древних историй Великой Британии» бургундского политика и писателя Жана де Ваврена (1398-1474). Автор не был англичанином и писал свое произведение на французском языке. К недостаткам его произведения относится большое количество неточностей и ошибок в описании происходящих на Британских островах событий. Однако у него мы находим упоминания трех участников [19, с. 269]. 


\section{ВСЕОБЩАЯ ИСТОРИЯ}

Другие хроники менее подробны, в основном в них лишь упоминается о сражении и его результате. К этому числу произведений относятся хроника лондонского рикордера Роберта Бэйла [14, с. 148], «Краткая английская хроника» [2, с. 72], «Хроника Лондона» 1089-1483 гг. [1, с. 140] и некоторые другие, практически ничего не дающие для достижения поставленной цели.

Новый виток конфликта стал очевиден уже в конце 1458 г., когда в Вестминстерском дворце было совершено нападение на одного из лидеров йоркистов Ричарда Невилля, графа Уорика. После этого противники правящего режима начали собирать силы: герцог Ричард Йорк - на границе с Уэльсом, граф Уорик - в Кале, а Ричард Невилль, граф Солсбери (отец Уорика) - в своих владениях в Йоркшире. В сентябре следующего года они начали объединять свои армии, пунктом сбора должен был стать город Ладлоу в Шропшире.

Ланкастерцы пытались помешать этому объединению. Но графу Уорику с 500 чел. [11, c. 223] удалось прибыть в Англию и благополучно добраться до Ладлоу, причем около Ковентри он чудом избежал столкновения с герцогом Сомерсетом (вероятно, идущим ему на перехват).

Граф Солсбери вел с севера, вероятно, более значительные силы: в источниках встречаются указания на 400 чел. [19, с. 269], 500 чел. [6, с. 204], 3 тыс. чел. [14, с. 140] и даже 4 тыс. чел. [2, с. 72]. Армия Ланкастеров, которой командовали Джеймс Туше, лорд Одли, и Джон Саттон, лорд Дадли, попыталась остановить его около местечка Блор Хит в Стаффордшире. В отношении численности ланкастерцев источники тоже сильно расходятся: 5 тыс. [6, с. 204], 6-8 тыс. чел. [19, c. 269], 12 тыс. чел. [14, с. 148], 14 тыс. [2, c. $140 ; 19$, с. 269]. Совершенно очевидно, что последние цифры сильно завышены, однако не вызывает сомнений, что армия Ланкастеров существенно превышала силы графа Солсбери. Несмотря на это, благодаря военной хитрости и тактике графа, победа досталась йоркистам. Ваврен говорит о 56 погибших с их стороны и 2 тыс. - со стороны Ланкастеров $[19$, c. 269].

Источники хранят молчание о подавляющем большинстве участников этого сраже- ния. Мы никогда не сможем узнать не только их имена, но и их сословную принадлежность и происхождение. Удалось идентифицировать лишь 22 человек.

\section{Сословная принадлежность участников сражения при Блор Хит}

\begin{tabular}{|c|c|c|}
\hline Социальный статус & Ланкастеры & Йорки \\
\hline Граф & - & 1 \\
\hline Лорды & 2 & - \\
\hline Рыцари & 10 & 6 \\
\hline Сквайры & - & 1 \\
\hline Не указан & 1 & 1 \\
\hline Всего & 13 & 9 \\
\hline
\end{tabular}

Наиболее подробная информация имеется о командирах. Ричард Невилль, граф Солсбери, являлся одним из крупнейших магнатов. Его сестра Сесили была женой герцога Ричарда Йорка. Однако в 1452 г. граф Солсбери еще не поддерживал своего зятя, он был в числе тех, кто вел переговоры с герцогом от имени короля Генриха VI. Сближение между ними произошло в последующие три года. На это мог оказать влияние конфликт между Невиллями и Перси за влияние в северных графствах, в котором вторые нашли поддержку короны, что должно было подтолкнуть графа Солсбери к сближению с оппозиционным герцогом [9, с. 85-93; 7, с. 321-364]. Именно благодаря поддержке Йорка граф Солсбери получил в 1454 г. высшую гражданскую должность лорда-канцлера, но уже в следующем году утратил ее.

Джеймс Туше, лорд Одли, был ветераном войн во Франции. Кроме того, значительная часть армии Ланкастеров была собрана в Чешире, а лорд Одли обладал там манорами $[18$, с. 11]. Вероятно, именно эти два обстоятельства повлияли на его назначение командующим. В сражении лорд Одли погиб, что, однако, не помешало его сыну Джеймсу поддержать в следующем году йоркистов [3, c. 95]. Другой командующий ланкастерцев Джон Саттон, лорд Дадли, также располагал землями в Чешире и соседнем Стаффордшиpe, имел опыт войн во Франции и уже сражался за Генриха VI в битве при Сент-Олбансе в 1455 г., где был ранен.

Больше всего известно имен рыцарей, и о большинстве из них удалось установить некоторые биографические данные. Среди йор- 
кистов было несколько довольно заметных персон. Прежде всего это Джон Невилль и Томас Невилль - сыновья графа Солсбери. Также присутствовало несколько дворян из северных графств, где влияние графа было значительным. Одним из людей Невиллей там был сэр Джон Коньерс из Йоркшира; его сын Джон состоял в браке с племянницей графа Солсбери, Элис, дочерью Уильяма Невилля, лорда Факонберга, который в это время удерживал по поручению графа Уорика стратегически важную английскую крепость на континенте - Кале.

Тесно связан с Невиллями был Томас Хэррингтон, шериф Йоркшира в 1455 году. Его матерью была Маргарет, дочь сэра Роберта Невилля из Хорнби. Сэр Томас погибнет, как и граф Солсбери, в битве при Уэйкфилде в следующем году. Его дети будут верными сторонниками Йорков: сыновья Джеймс и Роберт будут сражаться на их стороне вплоть до битвы при Босворте. В 1465 г. они будут принимать участие в аресте Генриха VI [15, c. 56-57].

Верным сторонником Невиллей вплоть до своей смерти в 1464 г. был Томас Парр, рыцарь из Уэстморленда. Его сыновья сэр Уильям Парр и сэр Джон Парр возвысятся при дворе Эдуарда IV. Сэр Уильям Парр будет одним из четверых наиболее доверенных лиц графа Уорика в северо-западном регионе, а затем, после падения графа, проводником королевской политики [4, с. 101, 145].

В рядах армии графа Солсбери находился сэр Уильям Стэнли - брат лорда Томаса Стэнли. В «Парламенте дьяволов» Палата Общин возложила вину за поражение ланкастерцев при Блор Хит на лорда Стэнли, который должен был присоединиться к королевской армии с 2 тыс. чел., но промедлил, находясь всего в 6 милях от места сражения [16, с. $369-$ 370]. Решение этого вопроса было отложено, и в дальнейшем Томас Стэнли не понес наказания. Что любопытно, лорд Стэнли был женат на Элеоноре, дочери графа Солсбери.

Также среди йоркистов были менее известные лица, такие как сэр Роджер Кинэстон из Шропшира, который будет сражаться на стороне йоркистов еще при Тьюксбери в 1471 г. [12, с. 105], и сквайр Томас Меринг из Йоркшира.
Что касается ланкастерцев, то помимо командующих лордов, наиболее заметными людьми среди них были сэр Джон Стэнли из Стаффордшира и сэр Уильям Тратбек из Чешира. Оба они находились в родстве с лордом Стэнли и сэром Уильямом Стэнли: сэр Джон Стэнли был их двоюродным дядей, а сэр Уильям Тратбек был женат на их родной сестре Маргарет. Сыновья обоих рыцарей через 20 с лишним лет выберут сторону Генри Тюдора, родственника и преемника Ланкастеров. Сэр Хамфри Стэнли, шериф Стаффордшира, будет сражаться за него при Босворте в 1485 г. [17, с. 116] и при Стоуке в 1487 г. [13, c. 187]. В последней битве за Генриха VII будет и сэр Уильям Тратбек [13, с. 187]. Кроме того, среди ланкастерцев в сражении при Блор Хит источники называют рыцарей из Чешира Джона Доуна и Хуго Винейблеса, контролера домохозяйства принца Уэльского Томаса Фиттона и Ричарда или Роберта Молинью из Ланкашира. Все эти люди, кроме Джона Стэнли, были в числе погибших.

Обращает на себя внимание, прежде всего, происхождение названных дворян. Вместе с графом Солсбери были в основном выходцы из северных и северо-западных областей, где позиции Невиллей выглядели наиболее сильными. Именно в этих областях граф мог рассчитывать на наибольшую поддержку. Однако, как мы знаем, он вел с собой лишь один из трех крупных отрядов, которые, объединившись, должны были сформировать армию Йорков.

Точно так же под командованием лордов Дадли и Одли была лишь часть тех сил, которые призвали под свои знамена Ланкастеры. Когда 12 октября две армии будут стоять друг напротив друга под стенами Ладлоу, в их рядах, по данным хроник, будет 20 тыс. чел. [14, с. 148$]$ у йоркистов и 30 тыс. чел. [6, с. 204] или 50 тыс. чел. [14, с. 148] у ланкастерцев. В ней будут представлены многие лорды, тогда как при Блор Хит сражались отряды, набранные в близлежащих графствах (Чешир, Стаффордшир, Ланкашир). По существовавшей в то время в Англии системе комплектования армий такие воинские формирования должны были набирать наиболее влиятельные в графствах люди, какими и были два лорда. Другие дворяне могли возглавлять от- 
дельные отряды, собранные в каждом графстве или даже его части. Скорее всего, именно их имена попали в хроники, которые обычно обращали внимание лишь на представителей элиты.

Общество позднесредневековой Англии было пронизано сетью личных связей и отношений, которые накладывали отпечаток на все стороны жизни, в том числе и на приверженность той или иной стороне в разгоревшемся конфликте. Особенно это видно на примере армии графа Солсбери, где большинство представителей высшего и среднего офицерского состава имели родственные связи (в том числе посредством браков) или же отношения покровительства. Перспективный анализ моделей социального поведения потомков упомянутых рыцарей показал, что, как правило, приверженность выбранному лорду переходила из поколения в поколение. Братья Томас и Уильям Стэнли, неоднократно оказывавшиеся в разных армиях, и в конце концов своим предательством при Босворте 1485 г. способствовавшие победе Генри Тюдора и прекращению борьбы за престол, выглядят как исключение из правила. Несмотря на все тонкости и противоречия междинастийной борьбы, английские рыцари во второй половине XV в. продолжали высоко чтить свои обеты верности и чести.

\section{СПИСОК ЛИТЕРАТУРЫ}

1. A Chronicle of London from 1089 to 1483 .L., 1827. $-324 \mathrm{p}$.

2. A Short English Chronicle// Three Fifteenth century Chronicles / ed. by J. Gairdner. - L., 1880. P. $1-80$.

3. An English Chronicle of the reigns of Richard II, Henry IV, Henry V and Henry VI written before the year 1471 / ed. by J. S. Davies. - L., 1856. - 252 p.

4. Booth, P. W. N. Landed Society in Cumberland and Westmorland, c. 1440-1485. The Politics of the Wars of the Roses / P. W. N. Booth. - Leicester, 1997. - 288 p.

5. Calendar of the Patent Rolls, preserved in the Public Record Office. Henry VI. Vol. 6 (1452-1461). L., 1971. - 1057 p.

6. Gregory's Chronicle // The Historical Collections of a Citizen of London in the Fifteenth Century/ ed. by J. Gairdner. - L., 1876. - P. 57-239.

7. Griffiths, R. A. King and Country: England and Wales in the Fifteenth Century/ R. A. Griffiths. L., 1991. $-417 \mathrm{p}$.
8. Grummitt, D. A Short History of the Wars of the Roses / D. Grummitt. - L., 2013. -257 p.

9. Hicks, M. Warwick the Kingmaker / M. Hicks. Oxford, 1998. $-360 \mathrm{p}$.

10. Hicks, M. A. The Wars of the Roses: 1455 1485 / M. A. Hicks. - Oxford, 2003. -98 p.

11. John Benets chronicle for the years 1400 to 1462 / ed. G. L. Harris. - L., 1972. - 233 p.

12. Paston Letters. 1422-1509. Vol. 5 / ed. by J. Gairdner. - L. : Exeter, 1904. -344 p.

13. Paston Letters. 1422-1509. Vol. 6 / ed. by J. Gairdner. - L. : Exeter, 1904. -340 p.

14. Robert Bale's Chronicle // Six Town Chronicles of England / ed. by R. Flenley. - Oxford, 1911. - P. 66-73.

15. Ross, C. D. Richard III / C. D. Ross. - Berkeley; Los-Angeles, 1983. $-265 \mathrm{p}$.

16. Rotuli Parliamentorum / ed. by J. Strachey [et al.]. - L., 1832. - Vol. 5. $-555 \mathrm{p}$.

17. The Ballad of Bosworth Field. - Electronic text data. - Mode of access: http://www.r3.org/richardiii/the-battle-of-bosworth/the-ballad-of-bosworthfield/. - Title from screen.

18. Twemlow, F. R. The Battle of Bloreheath /F. R. Twemlow. $-1912 .-86 \mathrm{p}$.

19. Wavrin, Jehan de. Recueil des ckoniques et anchiennes istories de la Grant Bretaigne, a present nomme Engleterre / Jehan de Wavrin ; ed. by W. Hardy. - L., 1891. - Vol. 5. - 756 p.

\section{REFERENCES}

1. A Chronicle of London from 1089 to 1483. London, $1827.324 \mathrm{p}$.

2. Gairdner J., ed. A Short English Chronicle. Three Fifteenth Century Chronicles. London, 1880, pp. 1-80.

3. Davies J.S., ed. An English Chronicle of the reigns of Richard II, Henry IV, Henry $V$ and Henry VI written before the year 1471. London, $1856.252 \mathrm{p}$.

4. Booth P.W.N. Landed Society in Cumberland and Westmorland, c.1440-1485. The Politics of the Wars of the Roses. Leicester, 1997. $288 \mathrm{p}$.

5. Calendar of the Patent Rolls, preserved in the Public Record Office. Henry VI. Vol. 6 (14521461). London, 1971. $1057 \mathrm{p}$.

6. Gregory's Chronicle. Gairdner J., ed. The Historical Collections of a Citizen of London in the Fifteenth Century. London, 1876, pp. 57-239.

7. Griffiths R.A. King and Country: England and Wales in the Fifteenth Century. London, 1991. $417 \mathrm{p}$.

8. Grummitt D. A Short History of the Wars of the Roses. London, 2013. 257 p. 
А.Г. Праздников. Социальный состав участников сражения при Блор Хит 23 сентября 1459 года

9. Hicks M. Warwick the Kingmaker. Oxford, $1998.360 \mathrm{p}$.

10. Hicks M.A. The Wars of the Roses: 14551485. Oxford, $2003.98 \mathrm{p}$.

11. Harris G.L.,ed. John Benets chronicle for the years 1400 to 1462 . London, 1972. $233 \mathrm{p}$.

12. Gairdner J., ed. Paston Letters. 1422-1509. Vol. 5. London, Exeter, 1904. 344 p.

13. Gairdner J., ed. Paston Letters. 1422-1509. Vol. 6. London, Exeter, 1904. 340 p.

14. Robert Bale's Chronicle. Flenley R., ed. Six Town Chronicles of England. Oxford, 1911, p. 66-73.
15. Ross C.D. Richard III. Berkeley; Los-Angeles, 1983. 265 p.

16. Strachey J., ed. (et al.). Rotuli Parliamentorum. Vol. 5. London, 1832. 555 p.

17. The Ballad of Bosworth Field. Available at: http://www.r3.org/richard-iii/the-battle-of-bosworth/ the-ballad-of-bosworth-field/.

18. Twemlow F.R. The Battle of Bloreheath, 1912. $86 \mathrm{p}$.

19. Wavrin Jehan de. Recueil des ckoniques et anchiennes istories de la Grant Bretaigne, a present nomme Engleterre. Vol. 5. London, 1891. 756 p.

\section{Information about the Author}

Andrey G. Prazdnikov, Candidate of Sciences (History), Associate Professor, Head of Department of History and Philosophy, Vyatka State Agrarian Academy, Prosp. Oktyabrskiy, 133, 610017 Kirov, Russian Federation, andrei-selek@mail.ru, http://orcid.org/0000-0002-8175-6971.

\section{Информация об авторе}

Андрей Геннадьевич Праздников, кандидат исторических наук, доцент, заведующий кафедрой истории и философии, Вятская государственная сельскохозяйственная академия, просп. Октябрьский, 133, 610017 г. Киров, Российская Федерация, andrei-selek@mail.ru, http: //orcid.org/0000-0002-8175-6971. 